\title{
Transmissive to Dark Electrochromic and Fluorescent Device Based on Poly(fluorene-bisthiophene) Derivative
}

\author{
Fred A. R. Nogueira, ${ }^{a}$ Ana Julia C. da Silva, ${ }^{b, c}$ Johnnatan D. de Freitas, ${ }^{a}$ \\ Amanda S. Tintino, ${ }^{b}$ Anna Paula L. A. Santos, ${ }^{b}$ Italo N. Oliveira ${ }^{d}$ and \\ Adriana S. Ribeiro ${ }^{\circledR *, b}$ \\ ${ }^{a}$ Departamento de Química, Instituto Federal de Alagoas, Campus Maceió, \\ 57020-600 Maceió-AL, Brazil \\ ${ }^{b}$ Instituto de Química e Biotecnologia, Universidade Federal de Alagoas, Campus A. C. Simões, \\ 57072-900 Maceió-AL, Brazil \\ 'Instituto Federal de Alagoas, Campus Batalha, 57420-000 Batalha-AL, Brazil \\ ${ }^{d}$ Instituto de Física, Universidade Federal de Alagoas, Campus A. C. Simões, \\ 57072-900 Maceió-AL, Brazil
}

\begin{abstract}
Films of a poly(fluorene-bisthiophene) derivative, named PFBT, were electrodeposited onto indium tin oxide (ITO) electrodes and their electrochromic and fluorescence properties were investigated. Such films displayed color variation from yellow, in the neutral state, to green, in the oxidized state, as shown by tracking of the CIE (Commission Internationale de l'Eclairage) $1931 \mathrm{xy}$ chromaticity coordinates. PFBT films are fluorescent in the neutral state $\left(\mathrm{E}=0.0 \mathrm{~V} v s . \mathrm{Ag} / \mathrm{Ag}^{+}\right)$ with emission at $532 \mathrm{~nm}$; however, upon oxidation at $0.85 \mathrm{~V}$ the photoluminescence intensity is significantly decreased. A solid-state electrochromic device was assembled using PFBT and poly(3,4-ethylenedioxythiophene) doped with poly(styrenesulfonate) (PEDOT-PSS) films and a polymer electrolyte. The device presented color variation from transmissive greenish-yellow to blue and reversible fluorescent properties upon switching between -1.5 to $1.5 \mathrm{~V} v s$. PEDOT. Thus, the high contrast and stability both in electrochromism and electrofluorescence of the PFBT film and its device make them suitable for application in multifunctional optical devices.
\end{abstract}

Keywords: conjugated polymer, fluorescence, spectroelectrochemistry, fluorene, thiophene derivative

\section{Introduction}

Conjugated polymers have attracted broad academic and industrial interest due to their applications in polymer light-emitting diodes (PLEDs), ${ }^{1}$ polymer solar cells (PSCs), ${ }^{2}$ electrochromic devices (ECDs) ${ }^{3,4}$ and fluorescent sensors. ${ }^{5}$ Such applications arise from their distinct optical and electronic properties, which can be tailored by modification of the monomer through attachment of different functional groups to the system. ${ }^{6-8}$ In recent years, multifunctional stimuli-responsive optical materials showing electrochemical switching of both coloration and emission based on conjugated polymers have been synthesized through incorporation of electroactive

*e-mail: aribeiro@qui.ufal.br fluorophores into the polymer main chain ${ }^{9}$ and their properties have been investigated aiming for application in electro-optical devices.

Fluorene and polyfluorene derivatives have been widely employed in PLEDs ${ }^{6}$ and PSCs ${ }^{10}$ due to their rigid planar structure, excellent hole-transporting properties, good solubility, exceptional chemical stability and photoluminescence efficiencies. ${ }^{11-13}$ Such structural versatility and interesting properties have led to the preparation of a wide variety of derivatives and copolymers based on polyfluorenes aiming to meet the requirements for organic optoelectronic devices assembly. ${ }^{14-16}$ For example, Cihaner and $\mathrm{Algi}^{17}$ have synthesized and characterized a processable rainbow mimic fluorescent polymer based on $\mathrm{N}$-substituted thienylpyrrole bearing a fluorene moiety, and Nie et al. ${ }^{18}$ have prepared a 3,4-ethylenedioxythiophene 
bis-substituted fluorene for application in optical devices, such as ECDs and PLEDs.

Thus, the preparation of extended $\pi$-conjugated systems based on the introduction of a fluorene bridge into the bisthiophene main chain can render multifunctional materials that exhibit both electrochromic and fluorescent properties..$^{9,19}$ Nevertheless, it is noteworthy that usually $\pi$-extended systems based on fluorene-bisthiophene polymers are mainly prepared by chemical approaches through Suzuki, Yamamoto and Stille reactions, ${ }^{20-23}$ and there are few reports concerning the electrochemical polymerization of these materials. Compared to the use of conventional chemical synthetic routes, the electrochemical polymerization directly onto an electrode surface presents several advantages, including the possibility of in situ investigation of the film growth process and control of thickness and morphology of the polymer film. ${ }^{9,24}$ However, to our knowledge, polymer films of fluorene derivatives electrodeposited directly onto an electrode surface can be obtained only by using boron trifluoride diethyl etherate (BFEE) as solvent ${ }^{13,25}$ or by applying high anodic potentials. ${ }^{18,26}$

Herein, a $\pi$-extended system based on fluorenebisthiophene, named 2,2'-(9,9-dioctyl-9H-fluorene2,7-diyl)bisthiophene (FBT), was electrochemically polymerized onto indium tin oxide (ITO) electrodes at relatively low potential and its polymer films (PFBT) were used to assemble a transmissive to dark fluorescent electrochromic device.

\section{Experimental}

\section{Materials and instrumentation}

Anhydrous acetonitrile $99.8 \%\left(\mathrm{CH}_{3} \mathrm{CN}<0.001 \%\right.$ water), lithium perchlorate $\left(\mathrm{LiClO}_{4}\right)$ and 2,2'-(9,9-dioctyl9H-fluorene-2,7-diyl)bisthiophene (FBT) were purchased from Sigma-Aldrich (St. Louis, United States) and used as received. Aqueous dispersion of poly (3,4-ethylenedioxythiophene) doped with poly(styrenesulfonate) (PEDOT-PSS, Clevios PH500) was furnished by Heraeus Precious Metals (Hanau, Germany). Poly(ethylene oxide-epychlorohydrin) (P(EO-EPI), co-monomer proportion $=84: 16$, molecular weight $\left.\left(\mathrm{M}_{\mathrm{W}}\right)=1300000 \mathrm{~g} \mathrm{~mol}^{-1}\right)$ produced by Daiso Co., Ltd. (Osaka, Japan) was used as polymer electrolyte to assemble the ECD.

Electrochemical experiments were carried out on an Autolab PGSTAT30 galvanostat/potentiostat. A HewlettPackard 8453A diode array spectrophotometer was employed to acquire the ultraviolet-visible-near infrared
(UV-Vis-NIR) spectra during spectroelectrochemical characterization. Scanning electron microscope (SEM) analysis was conducted on a Vega LM TESCAN Orsay Holdin microscope Thickness measurements were obtained using a NanoMap-500LS3D contact stylus surface profilometer (AEPTechnology). Fluorescence spectra were registered on a Fluorolog Horiba Jobin Yvon fluorometer at room temperature by front-face $\left(30^{\circ}\right)$ detection.

\section{Electropolymerization}

Poly[2,2'-(9,9-dioctyl-9H-fluorene-2,7-diyl) bisthiophene] (PFBT) films were deposited onto ITO electrodes (Delta Technologies, specific resistivity $(\mathrm{Rs})=8-12 \Omega \mathrm{cm}, 1.0 \mathrm{~cm}^{2}$ ) in a single compartment cell. A home-built non-aqueous $\mathrm{Ag} / \mathrm{Ag}^{+}$ $\left(0.1 \mathrm{~mol} \mathrm{~L}^{-1}\right.$ in $\left.\mathrm{CH}_{3} \mathrm{CN}\right)$ reference electrode $(+0.298 \mathrm{~V} v s$. normal hydrogen electrode; Analion), isolated from the working solution by a Vycor® frit, was used in the experiments. A Pt foil was employed as counter electrode.

FBT was used at a concentration of $5.0 \times 10^{-3} \mathrm{~mol} \mathrm{~L}^{-1}$ in a supporting electrolyte consisting of $0.10 \mathrm{~mol} \mathrm{~L}^{-1} \mathrm{LiClO}_{4}$ in $\mathrm{CH}_{3} \mathrm{CN}$. The PFBT films were electrodeposited onto ITO electrodes by potentiodynamic method $(0.0 \leq \mathrm{E} \leq 0.9 \mathrm{~V} v s$. $\mathrm{Ag} / \mathrm{Ag}^{+}$), in which the experimental conditions were varied to obtain films with 2 or 5 voltammetric cycles. After electrodeposition, the films were washed several times with $\mathrm{CH}_{3} \mathrm{CN}$ to remove unreacted monomers and excess electrolyte.

\section{Spectroelectrochemistry}

The polymer films deposited onto ITO were characterized by cyclic spectrovoltammetry and doublepotential-step spectrochronoamperometry in $0.10 \mathrm{~mol} \mathrm{~L}^{-1}$ $\mathrm{LiClO}_{4} / \mathrm{CH}_{3} \mathrm{CN}$ solution. A Pt wire was used as counter electrode, and an $\mathrm{Ag} / \mathrm{Ag}^{+}$electrode was employed as reference. Cyclic voltammograms were acquired within the potential scan range of $0.00 \leq \mathrm{E} \leq 0.85 \mathrm{~V}$ with a scan rate $(v)$ of $20 \mathrm{mV} \mathrm{s}^{-1}$ and chronoamperograms were obtained by applying pulses of $\mathrm{E}_{1}=0.00 \mathrm{~V}$ and $\mathrm{E}_{2}=0.85 \mathrm{~V}$ for $30 \mathrm{~s}$. UV-Vis-NIR spectra in the range of 300 to $1100 \mathrm{~nm}$ were recorded simultaneously with the electrochemical experiments.

CIE (Commission Internationale de l'Eclairage) 1931 $x y$ chromaticity coordinates ${ }^{27}$ were obtained by a Microsoft ${ }^{\circledR}$ Excel $^{\circledR}$ spreadsheet developed by Mortimer and Varley. ${ }^{28,29}$ To simulate mid-morning to mid-afternoon natural light, the relative power distribution of a D55 constant temperature (5500 K blackbody radiation) standard illuminant was used in the calculations. The CIE $1931 x y$ chromaticity 
coordinates were tracked in the CIE chromaticity diagram with Spectra Lux ${ }^{\circledR}$ Software v.2.0 Beta. ${ }^{30}$

\section{Electrochromic device assembly}

The PEDOT-PSS modified electrode was prepared by spraying an aqueous PEDOT-PSS solution onto ITO electrodes. The elastomeric polymer used as electrolyte was $\mathrm{P}(\mathrm{EO}-\mathrm{EPI}) / \mathrm{LiClO}_{4}$, which presents high ionic conductivity at room temperature. ${ }^{31}$ To assemble the device, $100 \mu \mathrm{L}$ of electrolyte solution containing $0.60 \mathrm{~g}$ of the elastomer and $0.032 \mathrm{~g}$ of $\mathrm{LiClO}_{4}$ in $10 \mathrm{~mL}$ of tetrahydrofuran ${ }^{32}$ were deposited on the surface of each electrode previously maintained in their neutral or oxidized form at 0.00 and $0.85 \mathrm{~V}$ vs. $\mathrm{Ag} / \mathrm{Ag}^{+}$, for the PFBT and PEDOT-PSS films, respectively. After solvent evaporation, the electrodes were carefully pressed against each other to obtain good adhesion. The ECD was assembled under atmospheric conditions with an active area $=1.0 \mathrm{~cm}^{2}$, and presented the following configuration:

ITO | PFBT || P(EPI-EO) / $\mathrm{LiClO}_{4}$ || PEDOT-PSS | ITO

For spectroelectrochemical characterization, the device was placed in the sample compartment of a Shimadzu Multispec 1501 spectrophotometer and connected to an Eco Chemie Autolab PGSTAT30 potentiostat in a two-electrode configuration. The PEDOT-PSS modified electrode was used as pseudo-reference (circuited with the counter electrode).

\section{Results and Discussion}

\section{Electropolymerization}

The cyclic voltammograms recorded during the electropolymerization of FBT (Figure 1) show that the onset oxidation potential $\left(\mathrm{E}_{\text {onset }}\right)$ is ca. $0.8 \mathrm{~V} v s$. $\mathrm{Ag} / \mathrm{Ag}^{+}$, which is lower than the $\mathrm{E}_{\text {onset }}$ reported for thiophene, ${ }^{5,33}$ bithiophene, ${ }^{24,34}$ fluorene and its derivatives. ${ }^{13,26}$ When compared with pristine thiophene, the introduction of a $\pi$ spacer, such as naphthalene, ${ }^{35}$ pyrene, ${ }^{36}$ carbazole, ${ }^{37-39}$ or fluorene, ${ }^{40}$ into a bisthiophene main chain modifies the degree of conjugation of the monomer due to the extended $\pi-\pi^{*}$ bonding system, displacing the $\mathrm{E}_{\text {onset }}$ towards less anodic potentials. Such behavior was observed for carbazolebisEDOT (where EDOT is 3,4-ethylenedioxythiophene), ${ }^{37}$ carbazole-bisthiophene ${ }^{38,39}$ and fluorene-bisEDOT ${ }^{18,41}$ systems, as can be seen in Table 1 .

On repetitive scanning the current of each peak is increased, implying that a layer of redox-active and

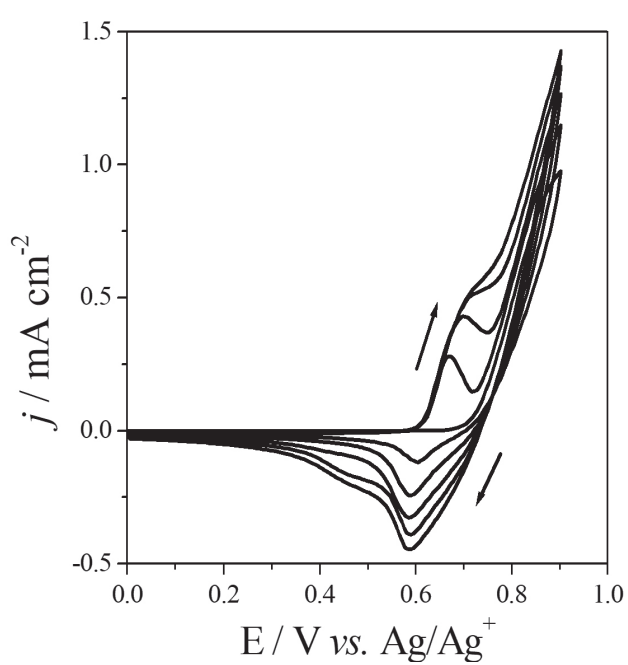

Figure 1. Cyclic voltammograms registered during electropolymerization of FBT in $0.1 \mathrm{~mol} \mathrm{~L}^{-1} \mathrm{LiClO}_{4} / \mathrm{CH}_{3} \mathrm{CN}$ with $v=0.02 \mathrm{~V} \mathrm{~s}^{-1}$.

conducting material was deposited on the electrode, with the formation of a redox couple of anodic peak potential (Epa) at ca. $0.7 \mathrm{~V}$ and cathodic peak potential (Epc) at ca. $0.6 \mathrm{~V}$. However, during the electropolymerization process it was observed the formation of soluble oligomers dislodging from the electrode surface. Such behavior may be ascribed to the presence of alkyl substituents in the fluorene moiety, which increases the solubility of the oligomer/polymer. ${ }^{20,42}$

\section{Morphological characterization of the PFBT films}

The potential cycling inherent to the potentiodynamic method creates a multinucleation growth process that results in a surface with globular grains, ${ }^{43,44}$ as can be seen in the representative SEM images of PFBT films deposited with 2 and 5 voltammetric cycles (Figure 2). The generic geometries of these films were similar with well-dispersed grains of mean radii $230 \pm 10 \mathrm{~nm}$ ( 2 cycles) and $667 \pm 60 \mathrm{~nm}$ ( 5 cycles).

According to Bock et al. ${ }^{45}$ the mean effective conjugation length varies according to film thickness and may be attributed to morphological changes during film growth. Such behavior was observed for the PFBT films electrodeposited with different voltammetric cycles, in which the thickness was ca. $0.42 \pm 0.07$ and $0.75 \pm 0.10 \mu \mathrm{m}$ for the films prepared with 2 and 5 cycles, respectively.

For application of the polymer film as active layer in ECDs a smooth morphology is advantageous in order to avoid scattering and clouding of incident light, which could interfere in the electrochromic performance of the device. Thus, thin films electrodeposited with 2 voltammetric cycles are more likely to be applied as electrochromic material for the ECD assembly. 
Table 1. Experimental conditions for the electropolymerization of thiophene, fluorene, and their derivatives, and $\pi$-extended systems based on carbazole, fluorene and bisthiophene derivatives

\begin{tabular}{|c|c|c|c|c|c|c|}
\hline Monomer & $\mathrm{E}_{\text {onset }}{ }^{\mathrm{a}} / \mathrm{V}$ & $\mathrm{WE}^{\mathrm{b}}$ & $\mathrm{RE}^{\mathrm{c}}$ & Electrolyte & $\mathrm{Eg}^{\mathrm{d}} / \mathrm{eV}$ & Reference \\
\hline & ca. 2.0 & $\mathrm{Pt}$ & $\mathrm{Ag} / \mathrm{AgCl}$ & $\mathrm{TBAP} / \mathrm{CH}_{3} \mathrm{CN}$ & 2.0 & $5,9,33$ \\
\hline & ca. 1.3 & $\mathrm{Pt}$ & $\mathrm{SCE}$ or $\mathrm{Ag} / \mathrm{AgCl}$ & $\mathrm{TBAP} / \mathrm{CH}_{3} \mathrm{CN}$ & - & 24,34 \\
\hline & $1.6-1.8$ & $\mathrm{Pt}$ & $\mathrm{Ag} / \mathrm{Ag}^{+}$ & $\begin{array}{c}\mathrm{TBAPF}_{6} / \mathrm{CH}_{2} \mathrm{Cl}_{2} \text { or } \\
\mathrm{TBABF}_{4} / \mathrm{CH}_{3} \mathrm{CN}\end{array}$ & - & 26 \\
\hline & $1.2-1.3$ & Pt or ITO & SCE & $\mathrm{BFEE}$ or BFEE / $\mathrm{CHCl}_{3}$ & - & 13 \\
\hline & 0.65 & Pt or ITO & $\mathrm{Ag} / \mathrm{AgCl}$ or $\mathrm{Ag}$ wire ${ }^{\mathrm{e}}$ & $\mathrm{TBABF}_{4} / \mathrm{CH}_{3} \mathrm{CN}$ & 2.5 & 38,39 \\
\hline & 0.45 & Pt or ITO & $\mathrm{Ag} / \mathrm{AgCl}^{\mathrm{e}}$ & $\mathrm{TBABF}_{4} / \mathrm{CH}_{2} \mathrm{Cl}_{2}$ & 1.68 & 37 \\
\hline & 1.7 & Pt or ITO & SCE & $\mathrm{TBABF}_{4} / \mathrm{CH}_{2} \mathrm{Cl}_{2}$ & 1.96 & 18 \\
\hline & 1.25 & $\mathrm{Pt}$ & $\mathrm{Ag} / \mathrm{AgCl}$ & $\mathrm{TBAPF}_{6} / \mathrm{CH}_{2} \mathrm{Cl}_{2}$ & 1.68 & 41 \\
\hline & 0.9 & ITO & $\mathrm{Ag} / \mathrm{Ag}^{+}$ & $\mathrm{LiClO}_{4} / \mathrm{CH}_{3} \mathrm{CN}$ & 2.27 & this work \\
\hline $\mathrm{R}=\mathrm{C}_{8} \mathrm{H}_{17}$ & & & & & & \\
\hline
\end{tabular}

${ }^{\mathrm{a} E l e c t r o c h e m i c a l ~ p o t e n t i a l ~ f o r ~ s t a r t i n g ~ e l e c t r o p o l y m e r i z a t i o n ; ~}{ }^{\mathrm{b}}$ working electrode; ${ }^{\mathrm{c}}$ reference electrode; ${ }^{\mathrm{d}}$ calculated for the polymer film; ${ }^{\mathrm{e}} \mathrm{calibrated} v \mathrm{~s}$. $\mathrm{Fc} / \mathrm{Fc}^{+}$. TBAP: tetrabutylammonium perchlorate; $\mathrm{SCE}$ : saturated calomel electrode; $\mathrm{TABPF}_{6}$ : tetrabutylammonium hexafluorophosphate; ITO: indium tin oxide; BFEE: boron trifluoride diethyl etherate.

\section{Spectroelectrochemical characterization of PFBT films}

PFBT films deposited onto ITO electrodes were characterized by cyclic spectrovoltammetry in monomerfree $0.1 \mathrm{~mol} \mathrm{~L}^{-1} \mathrm{LiClO}_{4} / \mathrm{CH}_{3} \mathrm{CN}$ solution in order to determine the potential window that would provide the maximum color contrast and to measure the wavelengths of maximum absorption $\left(\lambda_{\max }\right)$ of the film in the neutral and oxidized states. The cyclic voltammograms of the PFBT films displayed a well-defined redox pair with Epa at $0.78 \mathrm{~V}$ and Epc at $0.58 \mathrm{~V} v$ s. $\mathrm{Ag} / \mathrm{Ag}^{+}$(Figure 3a). The difference $(\Delta \mathrm{Ep})$ of $0.20 \mathrm{~V}$ between the anodic and cathodic 
(a)

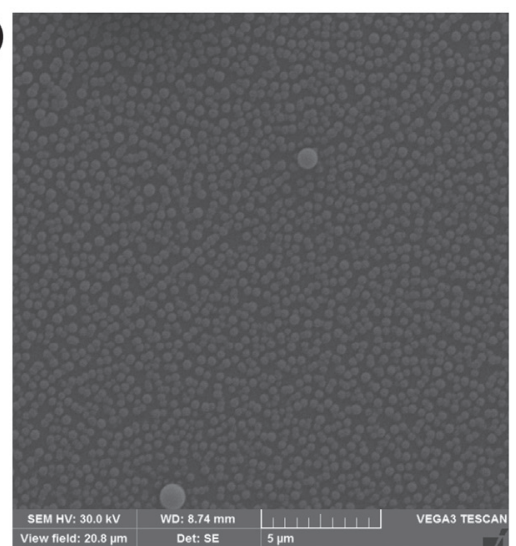

(b)

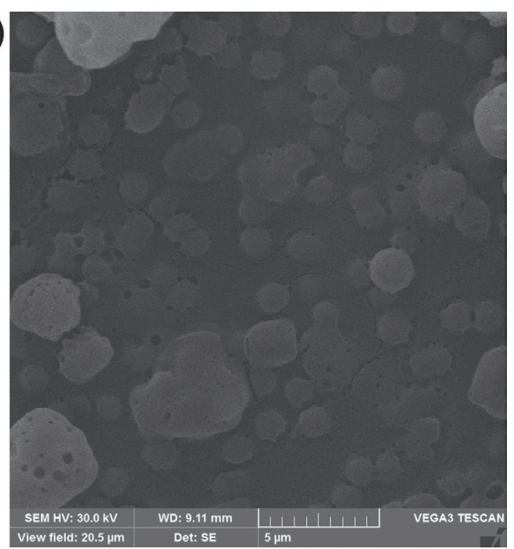

Figure 2. SEM images (mode SE) of PFBT film deposited onto ITO with (a) 2 and (b) 5 voltammetric cycles in $0.10 \mathrm{~mol} \mathrm{~L}^{-1} \mathrm{LiClO}_{4} / \mathrm{CH}_{3} \mathrm{CN}_{\text {. }}$
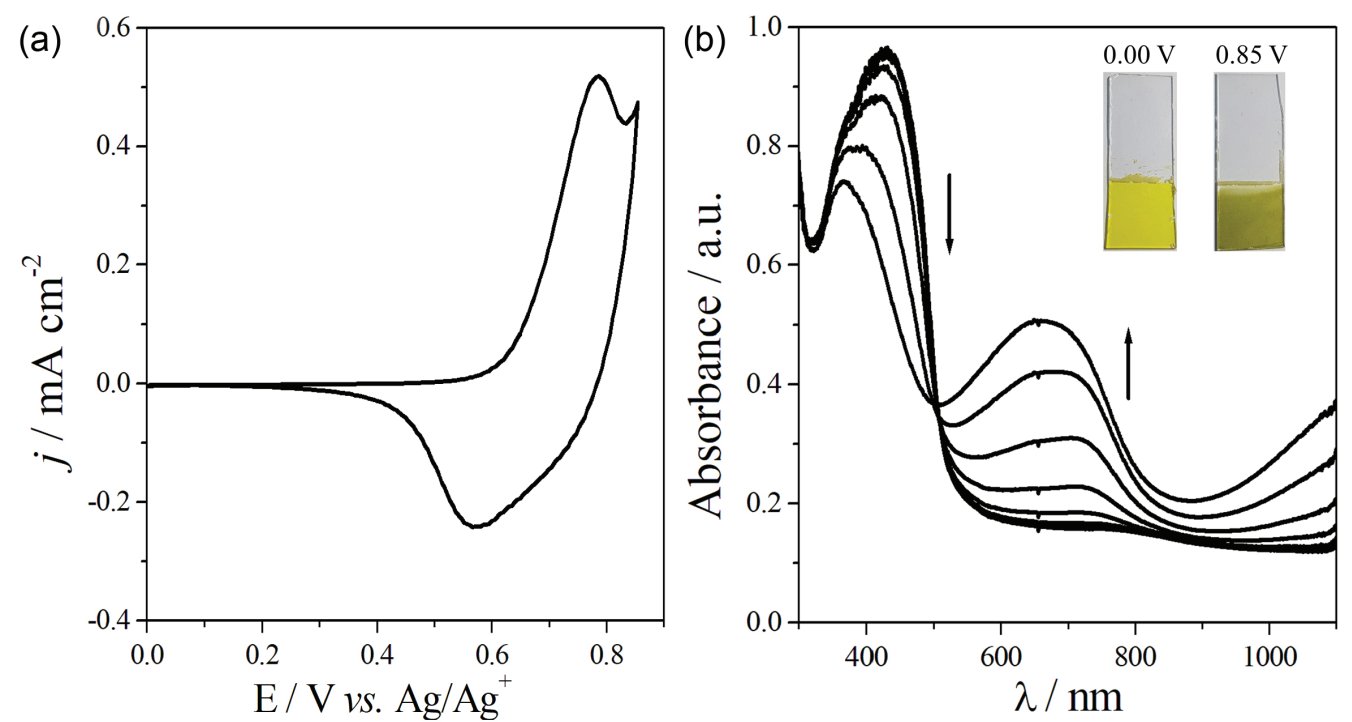

Figure 3. Spectroelectrochemical characterization of the PFBT film deposited onto ITO with 2 voltammetric cycles showing (a) the cyclic voltammogram of the film in $0.1 \mathrm{~mol} \mathrm{~L}^{-1} \mathrm{LiClO}_{4} / \mathrm{CH}_{3} \mathrm{CN}$ with $v=0.02 \mathrm{~V} \mathrm{~s}^{-1}$ and (b) the absorbance spectra as a function of the applied potential. Inset: images of the PFBT films at 0.00 (yellow) and $0.85 \mathrm{~V}$ (green) vs. $\mathrm{Ag} / \mathrm{Ag}^{+}$.

peak potentials may be explained by kinetic limitations like ion diffusion or interfacial charge transfer processes, including slow heterogeneous electron transfer, effects of structural reorganization processes within the polymer film, and electronic charging of a sum of two interfacial exchanges, namely the electrode/polymer and the polymer solution interfaces. ${ }^{46,47}$

The changes in the absorbance spectra of the PFBT film were plotted as a function of the potential applied to the electrode during cyclic voltammetry (Figure $3 b$ ). In the neutral state $(E=0.00 \mathrm{~V})$, the absorption spectrum of the PFBT film exhibits a band with a maximum $\left(\lambda_{\text {max }}\right)$ at $430 \mathrm{~nm}$. The band gap energy $(\mathrm{Eg})$ of $2.27 \mathrm{eV}$ was calculated from the onset of the $\pi-\pi *$ transition $\left(\lambda_{\text {onset }}=545 \mathrm{~nm}\right)$ in the absorption spectrum of the film at neutral state. According to the literature, ${ }^{9,48,49}$ usually Eg values for conjugated polymers are in the range of 1.5$3.0 \mathrm{eV}$, therefore, the Eg value found for PFBT is close to the values reported for similar $\pi$-conjugated systems, as shown in Table 1.

With increasing potential, the peak intensity of the band at $430 \mathrm{~nm}$ decreases, and it is displaced to ca. $650 \mathrm{~nm}$, which corresponds to the formation of the polaron state. The isosbestic point at $505 \mathrm{~nm}$ indicates that polymer film is undergoing interconversion between its neutral and oxidized states. At higher oxidation levels, a broad band in the NIR region (above $900 \mathrm{~nm}$ ) appears, and can be assigned to the formation of bipolarons, a consequence of the highly conducting state of the polymer film. ${ }^{50,51}$

In order to give an interpretation in terms of the changes in the spectral absorption bands as the colors seen by the human eye according to the potential applied to the system, the CIE $1931 x y$ chromaticity coordinates were calculated from the spectra of the PFBT film at potentials varying from 0.00 to $0.85 \mathrm{~V}$ and its trajectory is shown in Figure 4. The colors of the polymer film change from yellow (color 


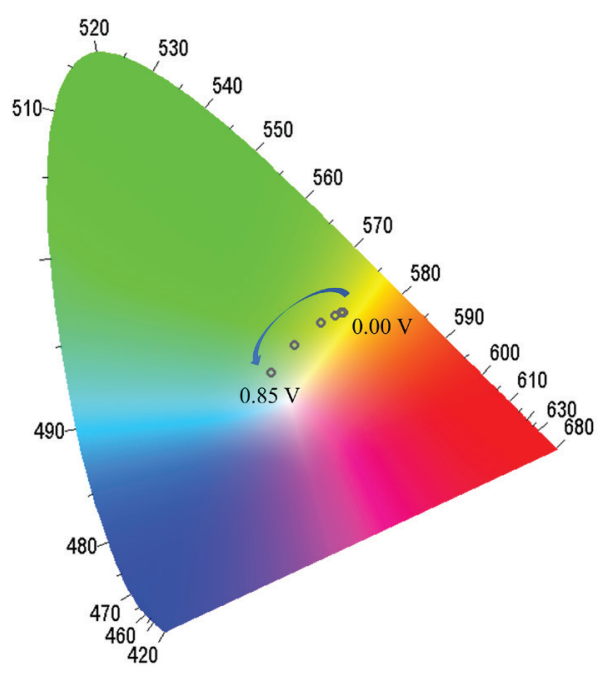

Figure 4. Calculated color trajectory in the CIE 1931 color space for the PFBT film deposited with 2 voltammetric cycles, with potential ranging from 0.00 to $0.85 \mathrm{~V} v s$. $\mathrm{Ag} / \mathrm{Ag}^{+}$.

coordinates: $x=0.428 ; y=0.460)$ in the neutral state to green $(x=0.324 ; y=0.373)$ in the oxidized state.

The relative luminance ( $\mathrm{Y}$, in percentage) can offer a different perspective on light transmittance of the film relative to spectroelectrochemistry where a low value of luminance corresponds to an opaque material while a high value is characteristic of a highly transparent material giving a perception of the changes in brightness. So both luminance and chromaticity coordinates provide valuable information that allows the observer to understand changes in the color of the material. ${ }^{29,52}$ The dependence of the relative luminance with the potential for PFBT films shows a great variation in $\mathrm{Y}$, as shown in Table 2, indicating that this material is suitable for application in transmissive to dark ECDs.

\section{Electrochromic switching of PFBT films}

The electrochromic performance of the PFBT films with respect to chromatic contrast ( $\Delta \mathrm{T}$, in percentage), response time and coloration efficiency $(\eta)$ was investigated by double step potential spectrochronoamperometry, which potential was swept between the neutral and fully oxidized states to monitor the changes in transmittance as a function of time. Figure 5 shows the optical response profiles of PFBT films at $650 \mathrm{~nm}$ as a function of time. The $\Delta \mathrm{T}$ of the PFBT films varied according to the number of voltammetric cycles applied during electrodeposition, i.e., film thickness, and it was found to be 35 and $50 \%$ at $650 \mathrm{~nm}$, for films electrodeposited with 2 and 5 cycles, respectively. Such films presented greater $\Delta \mathrm{T}$ when compared with polymer films of fluorene-bisEDOT ${ }^{47}(25 \%$ at $470 \mathrm{~nm})$ and fluorenone-EDOT ${ }^{41}(16.63 \%$ at $466 \mathrm{~nm})$ derivatives reported previously, indicating that PFBT films are good candidates as materials for ECD assembly.

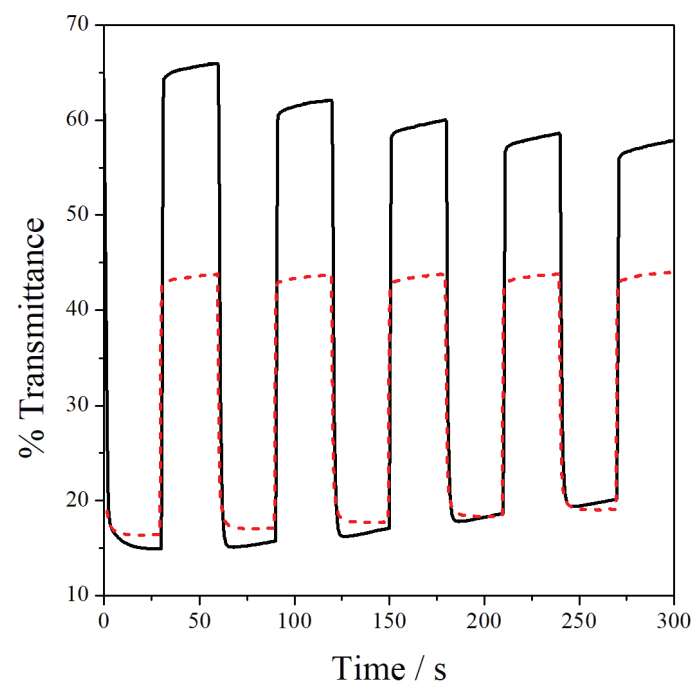

Figure 5. Transmittance variation at $650 \mathrm{~nm}$ of PFBT films deposited on ITO with 2 (-) and 5 (---) voltammetric cycles in $0.1 \mathrm{~mol} \mathrm{~L}^{-1}$ $\mathrm{LiClO}_{4} / \mathrm{CH}_{3} \mathrm{CN}$ solution upon potential switching $\left(\mathrm{E}_{1}=0.00 \mathrm{~V}\right.$ and $\left.\mathrm{E}_{2}=0.85 \mathrm{~V} v s . \mathrm{Ag} / \mathrm{Ag}^{+}\right)$.

The charge passed at $95 \%$ of the full optical switch is selected to evaluate response time, since the color change has taken place mostly at that level and the last $5 \%$ of the color change is difficult to perceive with the naked eye. The response time was calculated to be ca. $2 \mathrm{~s}$. Thus, PFBT films can be rapidly switched between the neutral and oxidized

Table 2. Colorimetry and electrochromic properties of the PFBT films and the electrochromic device according to the applied potential

\begin{tabular}{|c|c|c|c|c|c|c|}
\hline & $\mathrm{E} / \mathrm{V}$ & $x$ & $y$ & $\mathrm{Y} / \%$ & $\Delta \mathrm{T} / \%$ & $\eta /\left(\mathrm{cm}^{2} \mathrm{C}^{-1}\right)$ \\
\hline \multirow{2}{*}{ PFBT ( 2 cycles) } & 0.00 & 0.428 & 0.460 & 59.45 & \multirow{2}{*}{$50^{\mathrm{a}}$} & \multirow{2}{*}{$378^{\mathrm{a}}$} \\
\hline & 0.85 & 0.324 & 0.373 & 38.31 & & \\
\hline \multirow{2}{*}{ PFBT (5 cycles) } & 0.00 & 0.412 & 0.453 & 42.58 & \multirow{2}{*}{$28^{\mathrm{a}}$} & \multirow{2}{*}{$262^{\mathrm{a}}$} \\
\hline & 0.85 & 0.319 & 0.362 & 27.42 & & \\
\hline \multirow{2}{*}{ ECD } & -1.50 & 0.339 & 0.374 & 38.27 & \multirow{2}{*}{$20^{\mathrm{a}}$} & \multirow{2}{*}{$530^{\mathrm{a}}$} \\
\hline & 1.50 & 0.276 & 0.328 & 21.25 & & \\
\hline
\end{tabular}

${ }^{a}$ Calculated at $\lambda=650 \mathrm{~nm}$. E: electrochemical potential; Y: luminance; $\Delta \mathrm{T}$ : chromatic contrast variation; $\eta$ : coloration efficiency; PFBT: poly(fluorenebisthiophene) derivative; ECD: electrochromic device. 
states, corresponding to the ease of charge transport in the conducting film. ${ }^{53}$

The coloration efficiency $(\eta)$ is also an important characteristic for the electrochromic materials and it is obtained for a certain amount of the charge injected in the polymer as a function of the change in optical density. The $\eta$ values calculated for the films $\left(378\right.$ and $\left.262 \mathrm{~cm}^{2} \mathrm{C}^{-1}\right)$ are in accordance with the values cited in the literature ${ }^{18,47}$ for fluorene-based polymers $\left(250-415 \mathrm{~cm}^{2} \mathrm{C}^{-1}\right)$. Such results indicate that, concerning energy economy, PFBT is a promising material for application in optical devices, since a small amount of charge injected per area is necessary to obtain a perceptible change of color.

\section{Electrochromic device characterization}

Before assembling the device, it is necessary to equilibrate the charge used for the redox processes of the PFBT film in relation to a complementary electrode to improve the stability of the device during repetitive switching. Furthermore, the optical contrast of the device can be enhanced if the complementary electrode also presents electrochromic behavior with complementary color changes. Thus, in order to attain this effect, PEDOT-PSS was chosen as complementary electrochromic material to assemble the device, since PEDOT is well-known as an excellent electrochromic material displaying color variation from opaque deep blue in the reduced/neutral state with $\lambda_{\max }=615 \mathrm{~nm}$ to transmissive light-blue in the oxidized state. ${ }^{54,55}$ The ECD showed reversible response and high optical contrast upon switching between -1.50 and $1.50 \mathrm{~V}$ vs. PEDOT, changing its color from transmissive greenish-yellow to blue, Figure 6.

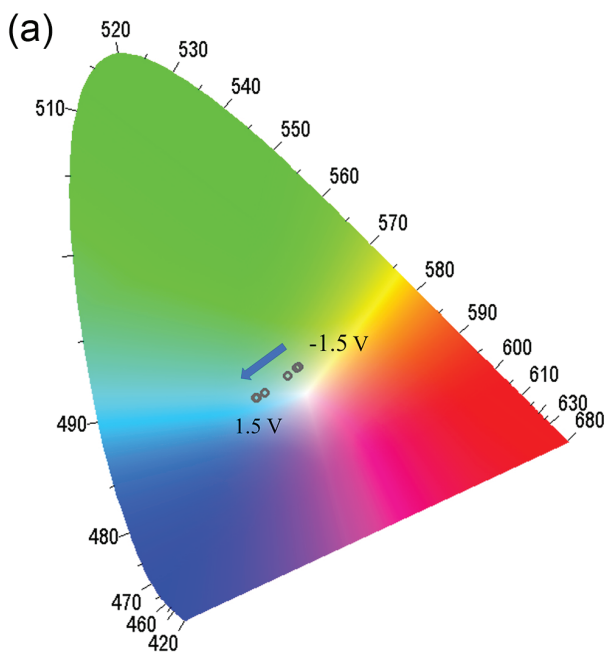

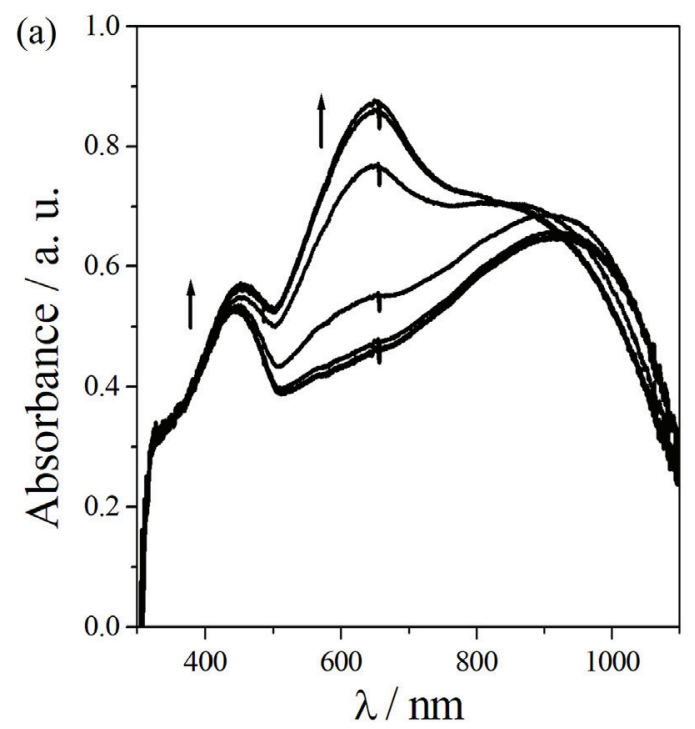

(b)

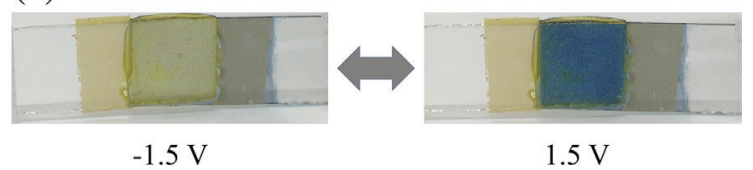

Figure 6. Spectroelectrochemical characterization of the ECD showing (a) the absorbance spectra as a function of the applied potential from -1.5 to $1.5 \mathrm{~V} v s$. PEDOT recorded every $0.5 \mathrm{~V}$ and (b) images of the ECD at -1.5 (greenish-yellow) and $1.5 \mathrm{~V}$ (blue) $v s$. PEDOT.

The color trajectory of the ECD given by the CIE $1931 x y$ chromaticity coordinates upon switching between -1.5 and $1.5 \mathrm{~V} v s$. PEDOT is shown in Figure 7 along with the variation of $\mathrm{Y}$ according to the applied potential. A perceptible variation of $\mathrm{Y}$ is interesting for application of the ECD as smart windows, since the difference between the transmissive and dark states is a desirable characteristic when it is aiming to provide ambient comfort in terms of illumination.

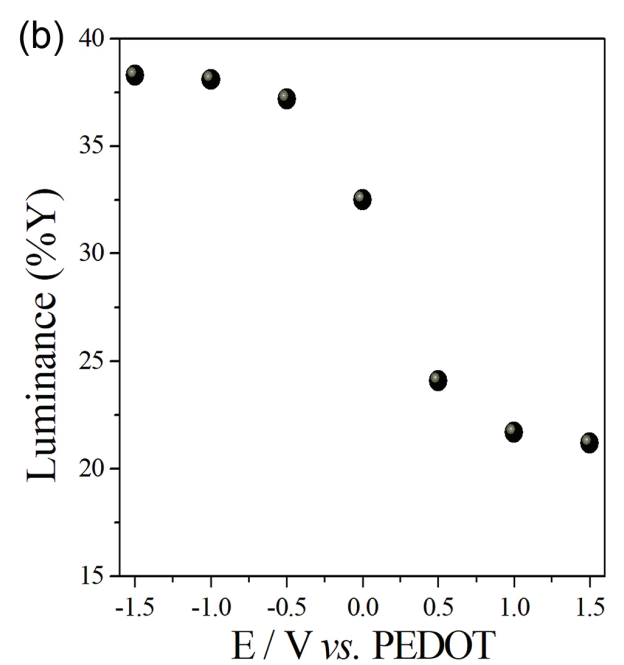

Figure 7. Calculated (a) color trajectory in the CIE 1931 color space and (b) luminance (Y) variation for the ECD upon potential switching from -1.5 to $1.5 \mathrm{~V}$ vs. PEDOT. 
The $\Delta \mathrm{T}$ of the device at $\lambda=650 \mathrm{~nm}$ was ca. $20 \%$. After 400 charge/discharge cycles, $\Delta \mathrm{T}$ decreased from 20 to $14 \%$, but the change from the transmissive to dark states still visually perceptible, Figure 8 . Due to the slow diffusion processes (charge transport) into the polymer electrolyte used to assembly the ECD, the response time was calculated as approximately $40 \mathrm{~s}$. Coloration efficiency calculated for the ECD was $530 \mathrm{~cm}^{2} \mathrm{C}^{-1}$, which can be considered as a great performance of the device when compared with other devices reported in the literature. ${ }^{3,49}$

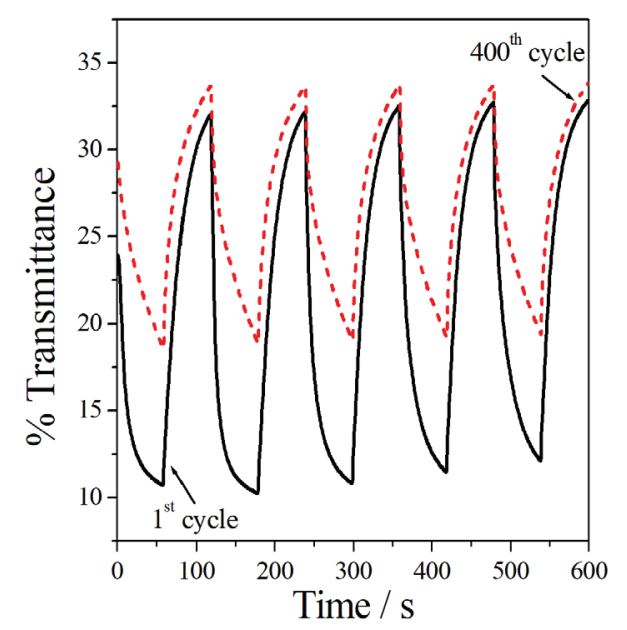

Figure 8. Transmittance variation at $650 \mathrm{~nm}$ of ECD upon potential switching $\left(\mathrm{E}_{1}=-1.5 \mathrm{~V}\right.$ and $\mathrm{E}_{2}=1.5 \mathrm{~V}$ vs. PEDOT), $1^{\text {st }}$ cycle $(-)$ and $400^{\text {th }}$ cycle (---).

\section{Fluorescent properties of the films and device}

The fluorescence spectra of FBT, neutral PFBT film dissolved in $N$-methylpyrrolidone (NMP) and the solid PFBT film are shown in Figure 9. The spectra of the monomer and polymer in solution show two emission bands at 454 and $490 \mathrm{~nm}$, and at 480 and $511 \mathrm{~nm}$, respectively, which can be associated to the $\pi-\pi^{*}$ transition of the aromatic ring. The red-shift observed in the emission of PFBT in NMP solution when compared to the monomer can be attributable to the increased conjugation of polymer backbone..$^{21,40}$

Usually the fluorescence of the solid film is greatly quenched owing to the aggregation of molecular chain and thus reducing the contrast of fluorescent/non-fluorescent state. ${ }^{16}$ Concerning PFBT, the fluorescent properties of the solid film were maintained, as can be seen in the spectrum shown in Figure 9. In such case, it was observed a single broad band at $532 \mathrm{~nm}$ with a red-shift in the emission of the solid film in comparison to the monomer and polymer in solution, since that, in the solid state the polymer self-aggregation tends to enhance the overlap between $\pi$ orbitals of the adjacent chains. . $^{13,40}$

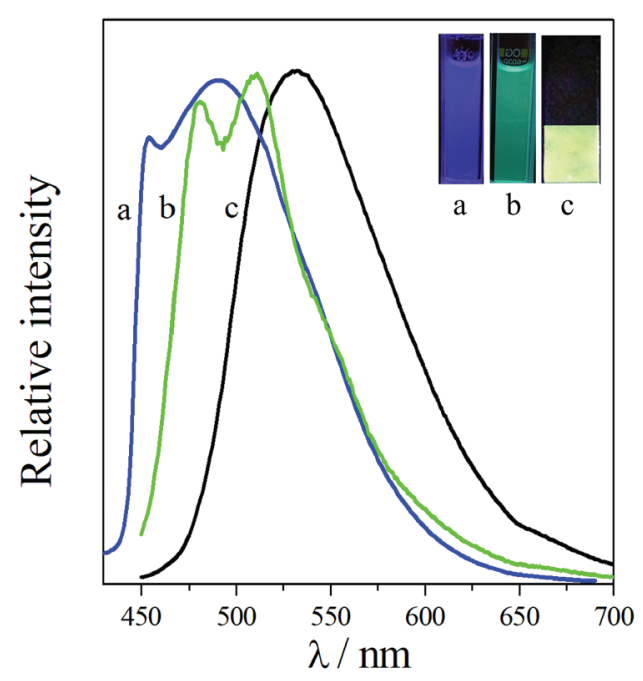

Figure 9. Emission spectra of the (a) FBT and (b) PFBT in NMP solution, and (c) PFBT film (solid state) when excited at 355 (monomer) and $430 \mathrm{~nm}$ (polymer). Inset: images of the monomer and polymer (solution and solid state) when exposed to $366 \mathrm{~nm}$ UV light.

Encouraged by the fluorescent properties of the PBFT film, the electrofluorescent switching performance of the as-prepared ECD was investigated by monitoring the photoluminescent response at different applied potentials as shown in Figure 10. Upon application of anodic potentials $(1.5 \mathrm{~V} v s$. PEDOT), the intensity of the emission band at $515 \mathrm{~nm}$ decreased to nearly zero and the fluorescence extinguished to dark. When the potential was subsequently set back to $-1.5 \mathrm{~V}$, the quenched fluorescence could be recovered and thus providing a high contrast between the fluorescent/non-fluorescent states.

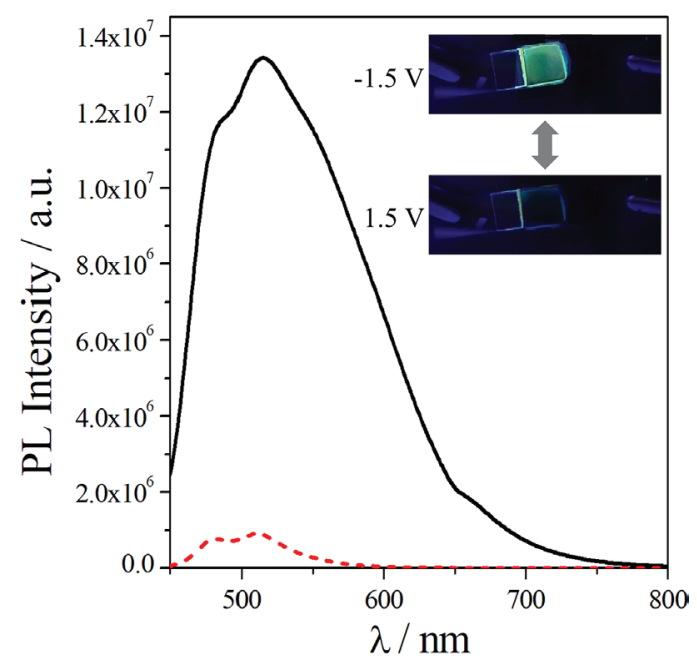

Figure 10. Fluorescence switching response of the device under applied potential from $-1.5 \mathrm{~V}$ (-) to $1.5 \mathrm{~V}(---) v s$. PEDOT. Inset: images of the DEC when exposed to $366 \mathrm{~nm}$ UV light.

Furthermore, the changes of the photoluminescence (PL) intensity occurred without a shift of the spectral 
band according to the applied potential, indicating that the fluorescence quenching originated from the electrochemical oxidation (polymer doping/undoping) with no formation of side products.

\section{Conclusions}

A conjugated polymer based on fluorene-bisthiophene derivative presenting electrochromic and fluorescent properties was electrodeposited onto ITO electrodes. The color of PBFT films varied according to the applied potential from yellow at $0.00 \mathrm{~V}$ to green at $0.85 \mathrm{~V}$ and encouraged the assembly of an electrochromic and fluorescent device based on such material. Thus, the high contrast between both transmissive to dark, and fluorescent/non-fluorescent states of the PFBT film and its device makes them suitable for application in multifunctional optical devices.

\section{Acknowledgments}

The authors wish to thank the granting authorities $\mathrm{CNPq}$ (process 442320/2014-0), CAPES, and FAPEAL (process 60030 393/2017) for financial support and for fellowship to A. J. C. S. (CAPES). The authors are particularly thankful to Centro de Tecnologia da Informação Renato Archer, Campinas, SP, by the spray deposition of PEDOT films; Daiso Co., Ltd., Osaka, for supplying the copolymer used for the electrolyte; and E. J. S. Fonseca and A. F. Sonsin from Laboratório de Caracterização e Microscopia de Materiais, GON (Grupo de Óptica e Nanoscopia) for the fluorescence analysis.

\section{References}

1. Teichler, A.; Shu, Z.; Wild, A.; Bader, C.; Nowotny, J.; Kirchner, G.; Harkema, S.; Perelaer, J.; Schubert, U. S.; Eur. Polym. J. 2013, 49, 2186.

2. Kim, B.-G.; Park, H. J.; Synth. Met. 2015, 199, 280.

3. Silva, A. J. C.; Nogueira, F. A. R.; Tonholo, J.; Ribeiro, A. S.; Sol. Energy Mater. Sol. Cells 2011, 95, 2255.

4. Wuang, H.; Barrett, M.; Duane, B.; Gu, J.; Zenhausern, F.; Mater. Sci. Eng., B 2018, 228, 167.

5. Atilgan, N.; Cihaner, A.; Önal, A. M.; React. Funct. Polym. 2010, 70, 244.

6. Almeida, A. K. A.; Dias, J. M. M.; Silva, A. J. C.; Santos, D. P.; Navarro, M.; Tonholo, J.; Goulart, M. O. F.; Ribeiro, A. S.; Electrochim. Acta 2014, 122, 50.

7. Coelho, E. C. S.; Nascimento, V. B.; Ribeiro, A. S.; Navarro, M.; Electrochim. Acta 2015, 178, 134.

8. Ayranci, R.; Ak, M.; New J. Chem. 2016, 40, 8053.
9. Ribeiro, A. S.; Mortimer, R. J. In Electrochemistry, vol. 13, $1^{\text {st }}$ ed.; Banks, C.; Mortimer, R.; McIntosh, S., eds.; Royal Society of Chemistry: Cambridge, UK, 2016, p. 21.

10. Satrijo, A.; Kooi, S. E.; Swager, T. M.; Macromolecules 2007, 40,8833 .

11. Bian, L.; Zhu, E.; Tang, J.; Tang, W.; Zhang, F.; Prog. Polym. Sci. 2012, 37, 1292.

12. Mahar, J.; Saeed, A.; Belfield, K. D.; Iqbal, A.; Irfan, M.; Shabir, G.; Larik, F. A.; Channar, P. A.; Dyes Pigm. 2017, 147, 385.

13. Xu, J.; Wei, Z.; Du, Y.; Zhou, W.; Pu, S.; Electrochim. Acta 2006, 51, 4771.

14. Guo, X.; Baumgarten, M.; Müllen, K.; Prog. Polym. Sci. 2013, 38, 1832.

15. Akpinar, H. Z.; Udum, Y. A.; Toppare, L.; Eur. Polym. J. 2015, $63,255$.

16. Sun, N.; Meng, S.; Zhou, Z.; Yao, J.; Du, Y.; Wang, D.; Zhao, X.; Zhou, H.; Chen, C.; RSC Adv. 2016, 6, 66288.

17. Cihaner, A.; Algi, F.; Electrochim. Acta 2008, 54, 665.

18. Nie, G.; Yang, H.; Chen, J.; Bai, Z.; Org. Electron. 2012, 13, 2167.

19. Yu, C.-Y.; Lin, W.-L.; Eur. Polym. J. 2014, 53, 246.

20. Idris, M.; Bazzar, M.; Guzelturk, B.; Demir, H. V.; Tuncel, D.; RSC Adv. 2016, 6, 98109.

21. Tang, W.; Ke, L.; Tan, L.; Lin, T.; Kietzke, T.; Chen, Z.-K.; Macromolecules 2007, 40, 6164.

22. Tsami, A.; Yang, X.-H.; Farrel, T.; Neher, D.; Holder, E.; J. Polym. Sci., Part A: Polym. Chem. 2008, 46, 7794.

23. Ziegler, E.; Pien, A.; Fischereder, A.; Trimmel, G.; Monatsh. Chem. 2011, 142, 193.

24. Wallace, G.; Tsekouras, G.; Wang, C. In Electropolymerization; Cosnier, S.; Karyakin, A., eds.; Wiley-VCH: New York, USA, 2010, ch. 11.

25. Lu, G. W.; Qu, L. T.; Shi, G. Q.; Electrochim. Acta 2005, 51, 340.

26. Hapiot, P.; Lagrost, C.; Floch, F. L.; Raoult, E.; RaoultBerthelot, J.; Chem. Mater. 2005, 17, 2003.

27. Wyszecki, G.; Stiles, W. S.; Color Science: Concepts and Methods, Quantitative Data and Formulae, $2^{\text {nd }}$ ed.; John Wiley and Sons: New York, USA, 1982.

28. Mortimer, R. J.; Varley, T. S.; Displays 2011, 32, 35.

29. Mortimer, R. J.; Varley, T. S.; Sol. Energy Mater. Sol. Cells 2012, 99, 213.

30. Santa-Cruz, P. A.; Teles, F. S.; Spectra Lux Software v.2.0 Beta; Ponto Quântico Nanodispositivos/RENAMI, Brasil, 2003.

31. Gazotti, W. A.; Spinace, M. A.; Girotto, E. M.; de Paoli, M.-A.; Solid State Ionics 2000, 130, 281.

32. Ribeiro, A. S.; Machado, D. A.; dos Santos Filho, P. F.; de Paoli, M.-A.; J. Electroanal. Chem. 2004, 567, 243.

33. Krische, B.; Zagorska, M.; Synth. Met. 1989, 28, C263.

34. Krische, B.; Zagorska, M.; Synth. Met. 1989, 33, 257.

35. Li, C.; Wang, M.; Cui, C.; Xu, L.; Wang, Z.; Kong, T.; Int. J. Electrochem. Sci. 2012, 7, 1214. 
36. Wen, H.; Gong, X.; Jia, Z.; Han, P.; Lin, B.; Ye, S.; Sun, Y.; Zhang, X.; Yang, H.; Dyes Pigm. 2016, 130, 16.

37. Data, P.; Zassowski, P.; Lapkowski, M.; Domaglia, W.; Krompiec, S.; Flak, T.; Penkala, M.; Swist, A.; Soloducho, J.; Danikiewicz, W.; Electrochim. Acta 2014, 122, 118.

38. Lapkowski, M.; Data, P.; Nowakowska-Oleksy, A.; Soloducho, J.; Roszak, S.; Mater. Chem. Phys. 2012, 131, 757.

39. Lapkowski, M.; Data, P.; Golba, S.; Soloducho, J.; NowakowskaOleksy, A.; Opt. Mater. 2011, 33, 1445.

40. Fu, Y.; Shi, L.; Zhu, D.; He, C.; Wen, D.; He, Q.; Cao, H.; Cheng, J.; Sens. Actuators, B 2013, 180, 2.

41. Bezgin, B.; Önal, A. M.; Electrochim. Acta 2010, 55, 779.

42. Henderson, P. T.; Collard, D. M.; Chem. Mater. 1995, 7, 1879.

43. Ribeiro, A. S.; Ribeiro, L. M. O.; Silva Jr., J. G.; Navarro, M.; Tonholo, J.; Microsc. Microanal. 2005, 11, 146.

44. Hillman, A. R.; Mallen, E. F.; J. Electroanal. Chem. 1987, 220 , 351.

45. Bock, A.; Topeters, A.; Kryschi, C.; Synth. Met. 1995, 75, 133.
46. Inzelt, G.; Pineri, M.; Schutze, J. W.; Vorotyntsev, M. A.; Electrochim. Acta 2000, 45, 2403.

47. Nie, G.; Qu, L.; Xu, J.; Zhang, S.; Electrochim. Acta 2008, 53 , 8351.

48. Camurlu, P.; RSC Adv. 2014, 4, 55832.

49. Beaujuge, P. M.; Reynolds, J. R.; Chem. Rev. 2010, 110, 268.

50. Chung, T. C.; Kaufman, J. H.; Heeger, A. J.; Wudl, F.; Phys. Rev. B 1984, 30, 702.

51. Sato, M.; Tanaka, S.; Kaeriyama, K.; Synth. Met. 1986, 14, 279.

52. Thompson, B. C.; Schottland, P.; Zhong, K.; Reynolds, J. R.; Chem. Mater. 2000, 12, 1563.

53. Lincker, F.; Delbosc, N.; Bailly, S.; Bettignies, R. D.; Billon, M.; Pron, A.; Demadrille, R.; Adv. Funct. Mater. 2008, 18, 3444. 54. Sonmez, G.; Sonmez, H. B.; J. Mater. Chem. 2006, 16, 2473.

55. Sonmez, G.; Chem. Commun. 2005, 42, 5251.

Submitted: July 11, 2019

Published online: August 26, 2019 